\title{
EFEITOS DOS POLUENTES ATMOSFÉRICOS SOBRE PLACAS DE ROCHAS CARBONÁTICAS NOS REVESTIMENTOS DE EDIFICAÇÕES EM REGIÃO LITORÂNEA DO RECIFE - PE
}

\author{
S. A. DA SILVA ${ }^{1 *}$, F. M. C. OLIVEIRA ${ }^{2}$, E. ALBUQUERQUE MENOR ${ }^{2}$, E. B. MELO ${ }^{2}$ e J. A. NOGUEIRA NETO ${ }^{1}$ \\ ${ }^{1}$ Universidade Federal do Ceará \\ ${ }^{2}$ Universidade Federal de Pernambuco \\ suelyandradeufc@gmail.com*
}

Artigo submetido em dezembro/2014 e aceito em dezembro/2014

DOI: $10.15628 /$ holos.2014.2613

\section{RESUMO}

Os particulados e/ou aerossóis são poluentes para as rochas de revestimentos. Sendo uma mistura de partículas muito pequenas dispersas na atmosfera na forma de sólidos ou de líquidos, podem ser produto da nebulização de substância líquida ou sólida ou da condensação da fase gasosa (queima de combustíveis fósseis, etc). Fluxos de calor e vapor entre a atmosfera e a rocha favorecem ou impedem o depósito na superfície de gases e partículas. Esses fluxos ingressam para o interior das rochas e facilitam migrações de sais, formação de eflorescências, microfraturas, desenvolvimento de organismos, perda de brilho e manchas. A preservação do lustro e a susceptibilidade ao intemperismo dos mármores Bege Bahia, dependem da composição mineralógica. A calcita é o minera dominante, a vulnerabilidade se manifesta no aspecto físico, em decorrência da baixa dureza (3) e no químico, onde a reatividade com produtos ácidos, inclusive a própria chuva, resulta em perda de reflectância e dissolução. As oscilações diárias da umidade relativa, em Recife, cerca de 80\%, favorecem a cristalização e dissolução dos sais, sendo condições ideais para processos de alteração nos revestimentos, como manchas, destacamentos líticos, eflorescências e desagregações. Os mármores, principalmente os calcários sedimentares, apresentam alterabilidade precocemente e arenização, por vezes, com menos de 5 anos de aplicação, se não forem resinados.

PALAVRAS-CHAVE: Aerossóis marinhos, alterabilidade, revestimentos carbonáticos, spray marinho.

\section{EFFECTS OF AIR POLLUTANTS ON CARBONATE ROCKS PLATES IN CLADDINGS OF BUILDINGS IN THE COASTAL REGION OF RECIFE - PE}

\section{ABSTRACT}

Particulates and/or aerosols are harmful pollutants to cladding rocks. They are a mixture of very small particles dispersed in the atmosphere in the form of liquid or solid and may be product from the nebulization of liquid or solid substances or condensation from the gaseous phase (burning fossil fuels, etc). Fluxes of heat and vapor between the atmosphere and the rock favor or impede the deposit on the surface of particles and gases, they enter the interior of rocks, which facilitate migration of salts, formation of efflorescence, microfractures, loss of gloss, stains and development of organisms. The preservation of brightness and susceptibility to weathering of the marbles Bege Bahia depend on the
\end{abstract}

mineralogical composition. The calcite is the dominant mineral: the vulnerability manifests in the physical domain, due to the low hardness (3) and in the chemical, where the reactivity with acid products (including rain itself) results in loss of reflectance and dissolution. Daily changes in relative humidity, in Recife, around $80 \%$, favor the crystallization and dissolution of salts, being ideal conditions for change processes in claddings such as stains lithic detachments, efflorescence and disaggregation. Marbles, mainly sedimentary limestones, present early changeability and arenization, sometimes, under 5 years of application, if not resined.

KEYWORDS: Marine aerosols, changeability, carbonate claddings, marine spray. 


\section{INTRODUÇÃO}

A rocha, desde os tempos mais remotos, faz parte da vida do homem. Na antiguidade e mesmo na Pré-História, ela, a rocha, aparece ligada à história da humanidade. Não sem razão, alguns períodos da pré-história recebem nomes ligados a ela: Neolítico, Paleolítico. O material pétreo foi usado na construção de palácios, castelos, templos religiosos, ora como material de sustentação, ora como elemento decorativo. Atualmente este material assume ainda vários empregos na construção civil, seja como elemento estrutural fazendo parte de concretos e lastros de vias férreas, seja como material de revestimento com a dupla função de proteger e embelezar a obra de engenharia.

Como elemento de revestimento, a rocha deve atender a requisitos estéticos e técnicos que possibilitem seu uso de forma que o trinômio durabilidade-beleza-custo seja plenamente atendido.

Os revestimentos pétreos das fachadas dos prédios estão submetidos à ação das intempéries. O clima, traduzido principalmente pela quantidade média de chuvas, temperaturas médias e insolação, exerce função primordial no decaimento do material pétreo. Também, o aumento da poluição atmosférica atua de maneira sinérgica intensificando os processos de degradação e decomposição das rochas.

A cidade do Recife, capital do estado de Pernambuco, encontra-se a baixa latitude, em região de pluviosidade elevada (média de $2.000 \mathrm{~mm}$ ), temperaturas médias também altas $\left(27^{\circ} \mathrm{C}\right)$ e número elevado de horas de insolação (média mensal de 211 horas de sol). Os revestimentos externos dos prédios da região litorânea deste município estão submetidos à ação deste clima e também, devido à proximidade do mar, à ação dos aerossóis marinhos. Rochas carbonáticas são bastante usuais como revestimentos externos de prédios na orla do Recife. Em geral, sua cor clara, portanto neutra, atrai a atenção dos arquitetos que usam este material de forma indiscriminada.

Neste contexto, o propósito trabalho foi estudar os efeitos da poluição atmosférica sobre as placas pétreas dos revestimentos carbonáticos externos de construções litorâneas da cidade do Recife.

\subsection{POLUENTES ATMOSFÉRICOS E AS ROCHAS}

Os particulados ou aerossóis integram a lista dos elementos poluentes mais prejudiciais para as rochas de revestimentos. Podem ser definidos como uma mistura de partículas suficientemente pequenas dispersas na atmosfera sob a forma de sólidos ou de líquidos (em gotas), como produtos de nebulização de substâncias líquidas ou sólidas, spray marinho ou tempestade de poeira, e da condensação da fase gasosa (fumaça produzida pelas indústrias). Assumem, ainda, importância relevante as pequenas diferenças espaciais que criam gradientes entre a atmosfera e a rocha, como também as variações temporárias destes gradientes que, por sua vez, criam processos de degradação relacionados com diferentes tempos de adaptação entre a atmosfera e a rocha. Deste modo, geram-se fluxos de calor e de vapor entre o ambiente e a rocha. Muitas vezes são estes fluxos que favorecem ou impedem o depósito na superfície das rochas de gases e partículas, que promovem o ingresso de vapores para o interior das rochas, 
que facilitam migrações de sais, a formação de eflorescências, microfraturas, perda de brilho, manchas e a criação de condições adequadas ao desenvolvimento de organismos diversos (AIRES-BARROS, L, 1991).

Os danos detectados nos revestimentos de fachadas e de monumentos podem advir de diversas substâncias químicas, existentes na forma de gases (aproximadamente $90 \%$, em peso, dos poluentes), líquidos (aerossóis) ou particulados. Podem ser lançados diretamente no ar (poluentes primários) ou podem ser criados no ar (poluentes secundários), a partir de outros poluentes sob a influência da radiação eletromagnética do sol. O resultado das reações entre estes contaminantes é danoso para os materiais pétreos, provocando em alguns casos o colapso total dos mesmos (FRASCÁ, 2003).

Nos monumentos situados próximos à região litorânea, notadamente aqueles próximos ao mar, deve-se considerar a ação do íon cloro que provem fundamentalmente da névoa salina e aerossóis transportados pelo vento e que é rica em sais marinhos notadamente $\mathrm{NaCl}$. A presença simultânea na atmosfera contaminada do $\mathrm{Cl}^{-}$e demais elementos têm um efeito sinergético na degradação das rochas e monumentos. $\mathrm{O} \mathrm{SO}_{2}$ deixa como vestígio as crostas negras tão típicas nos monumentos construídos com rochas calcárias e que são encontradas, também, nos revestimentos de edifícios com placas dos mais diferentes tipos de rochas. $\mathrm{O}_{\mathrm{CO}_{2}}$ é um componente do ar atmosférico, mas quando presente em excesso devido à queima de madeira, carvão, papel e outros materiais, impede que parte do calor terrestre seja irradiada prontamente para o espaço, devido à absorção da radiação infravermelha, sendo responsável pelo efeito estufa. Aqui cabe dizer que o excesso de $\mathrm{CO}_{2}$, combinado com a água de chuva contribui para a formação de ácido carbônico que, embora fraco, atua diuturnamente sobre os materiais pétreos alterando-os. O NOx, uma combinação de $\mathrm{NO} \cdot$ e $\mathrm{NO}_{2}$, são espécies que se originam principalmente da queima de combustível fóssil nos motores de explosão e de algumas indústrias. Estes compostos são poluentes primários e fundamentais para a geração de $\mathrm{HNO}_{3} \mathrm{a}$ partir do fenômeno denominado de smog fotoquímico. (RIBEIRO, 2011).

Nas zonas litorâneas, o arrebentamento das ondas marinhas libera para a atmosfera pequenas gotículas de água, que constituem a maresia ou o spray marinho (aerossóis marinhos) ocorrendo precipitação dos sais nelas contidos durante a sua evaporação. Desta forma, no litoral, a composição da precipitação é semelhante à composição da água do mar. À medida que se adentra no continente, diminui a concentração dos elementos derivados do spray marinho. A evaporação da água das gotículas produz aerossóis com diferentes tamanhos. As partículas maiores atingem dimensões da ordem de $10 \mu \mathrm{m}$ e retêm a composição das gotículas parentais. Pelo contrário, nas de menores dimensões ocorre modificação da composição química inicial. Com efeito, pode haver evaporação do cloreto sob a forma de $\mathrm{HCl}$, provocando depleção neste elemento relativamente ao sódio. O cloreto de sódio é um importante componente dos sprays marinhos cuja reação com ácido sulfúrico obtido da oxidação do $\mathrm{SO}_{2}$ atmosférico pode gerar ácido clorídrico.

Segundo Berner e Berner (1987), os aerossóis repartem-se, em geral, como $27 \%$ de sais marinhos transportados pelo vento, $17 \%$ de sulfatos solúveis, nitratos e amônia, formados por emissões gasosas naturais ou antropogênicas, e $41 \%$ como poeiras de solos e rochas. Estas percentagens podem ser muito variadas tanto no espaço como no tempo. Os aerossóis incluem ainda uma pequena participação de particulados produzidos em incêndios florestais, em atividades agrícolas, ou derivadas de emissões antropogênicas diretas e por hidrocarbonetos. No Brasil, país de extensa costa ocupada por cidades com elevada densidade urbana, esta 
circunstância assume papel relevante na alteração dos revestimentos em função de altos índices de corrosividade. Os danos em rochas graníticas e mármores expostos nestes ambientes, resultam da acumulação de sais devido à migração das soluções salinas por meio da rede de porosidade destas litologias. Este processo se inicia pela penetração de águas pluviais, pelas condensações da umidade, ou por águas de capilaridade provenientes do solo, resultando em migração no sistema poroso das rochas até que ocorram processos de evaporação. Quando migram de dentro para fora da rocha, as soluções salinas lixiviam e transportam para as superfícies componentes das rochas e da alvenaria, e dissolvem depósitos atmosféricos encontrados na superfície das mesmas. Em ambientes próximos ao mar, os sais depositados em rochas podem ser provenientes da névoa salina ou de soluções salinas oriundas dos solos (ou da própria rocha). Porém, se estas rochas apresentarem características idênticas e exposições equivalentes, ainda assim elas podem apresentar diferentes formas de alterabilidade.

Mehta e Monteiro (1994) descreveram que a maioria das águas marítimas é razoavelmente uniforme quanto à composição química. No oceano Atlântico, o teor total médio de sais é de $35 \%$ (35 g/L). A quantidade dos principais íons, contidos nas águas oceânicas, é indicada na Tabela 1.

Tabela 1 - Principais íons contidos em águas do Oceano Atlântico

\begin{tabular}{c|c}
\hline ÍONS & CONCENTRAÇÃO DOS ÍONS (mg/L) \\
\hline $\mathrm{SO}_{4}$ & 2.800 \\
\hline $\mathrm{Mg}^{++}$ & 1.300 \\
\hline $\mathrm{Ca}^{++}$ & 400 \\
\hline $\mathrm{Cl}^{-}$ & 19.900 \\
\hline $\mathrm{Na}+$ & 11.000 \\
\hline $\mathrm{K}^{+}$ & 400
\end{tabular}

Considerando-se os íons dominantes existentes em águas marinhas francas, observa-se que em suas composições salinas (Tabela 2) o principal sal dissolvido é o cloreto de sódio, seguido de cloreto de magnésio, ambos representando aproximadamente $88 \%$ da composição total. Sulfatos de Ca e de $\mathrm{Mg}$ integram em torno de $10 \%$ desta composição total. Assim, os sprays marinhos são principalmente compostos de cloretos, sais de grande solubilidade.

Tabela 2 - Composição da água do mar FORSCHHAMMER (apud BICZÓK, 1972)

\begin{tabular}{c|c|c}
\hline SAL & g/L & \% EM RELAÇÃO AO SAL TOTAL \\
\hline Cloreto de sódio & 26,9 & $\mathbf{7 8 , 3 2}$ \\
\hline Cloreto de magnésio & 3,2 & 9,44 \\
\hline Sulfato de magnésio & 2,2 & 6,40 \\
\hline Sulfato de Cálcio & 1,3 & 3,94 \\
\hline Cloreto de cálcio & 0,6 & 1,69 \\
\hline $\begin{array}{c}\text { Outros (Sulfato de potássio, } \\
\text { bicarbonato de cálcio, etc.) }\end{array}$ & & 0,21 \\
\hline Total & $\mathbf{3 4 , 3}$ & $\mathbf{1 0 0 , 0 0}$ \\
\hline
\end{tabular}

\section{2 ÁREA DE ESTUDO}

A área de estudo está encravada no litoral da Região Metropolitana de Recife, capital de Pernambuco, banhada pelo Oceano Atlântico, estando delimitada pelas coordenadas geográficas: $32 \circ 52^{\prime} 02^{\prime \prime} / 34^{\circ} 53^{\prime} 47^{\prime \prime}$ de longitudes $W$, e 8o 05' 02" /8 08' 06" de latitudes $S$ de Greenwich. 
Recife nasceu na foz dos rios Capibaribe e Beberibe. Além dos rios, Recife possui inúmeros canais e pontes, e por isso é conhecida como a "Veneza brasileira". A temperatura média anual da área é de $24{ }^{\circ} \mathrm{C}$, variando entre a mínima de $18{ }^{\circ} \mathrm{C}$ e a máxima de $32 \mathrm{C}$, sendo fortemente influenciada pela ação dos ventos dominantes, os alísios de SE (quentes e secos) e NE (quentes e úmidos). A pluviosidade é elevada, cerca de $2.000 \mathrm{~mm} /$ ano, concentrada nos meses de maio a agosto. Este domínio litorâneo conta com uma população de mais de 100 mil habitantes distribuídos entre os bairros de Boa Viagem, Pina e Brasília Teimosa. As praias da Boa Viagem e do Pina têm uma área de 57,48 hectares e cerca de $8 \mathrm{~km}$ de extensão. A área tem como limites: ao norte, o bairro de Brasília Teimosa; ao sul, a praia de Piedade, pertencente ao município de Jaboatão dos Guararapes; a leste, o Oceano Atlântico e a oeste o bairro de Boa Viagem, o parque dos manguezais, o canal do Rio Jordão e o canal Setúbal.

\section{METODOLOGIA}

\subsection{Amostragem}

Para o desenvolvimento desta pesquisa foi feita uma visita à área para viabilizar as atividades de campo, demarcar os pontos de coletas, registro de fotografias e criar condições para realização das etapas laboratoriais das amostras coletadas in loco. Foram observados os vários revestimentos em prédios localizados em avenida litorânea. Foram considerados aqueles de natureza carbonática tal qual o Mármore Branco e o Travertino, que apresentam boa freqüência de aplicação. Os critérios para seleção das placas pétreas estudadas foram a composição mineralógica, no caso material carbonático, grau de alteração, e a degradação das placas pétreas do revestimento. A qualificação e/ou quantificação das alterações mineralógicas ocorridas foram realizadas por meio de análises petrográficas. Também, foram considerados os tempos de aplicação dos revestimentos nas fachadas das edificações, que variaram entre 5 e 20 anos. Amostras de material usado, retirado durante reparos, foram usadas para obtenção de lâminas petrográficas.

A descrição petrográfica, envolvendo a identificação mineralógica e feições texturais das rochas, foi realizada com a utilização de um microscópio Olympus BX40, dotado de sistema digital fotomicrográfico.

\section{RESULTADOS E DISCUSSÃO}

As características mineralógicas dos litotipos analisados (Tabela 3) mostram que os materiais carbonáticos, mármores e calcários, são dominantemente calcíticos. O material Mármore Branco foi designado por $\mathrm{MBC}$ e o Travertino por BB (Bege Bahia). O mineral dominante nas duas rochas é calcita; entretanto o Bege Bahia apresenta mica (flogopita) e opacos, e o mármore branco margarita (mica) como minerais acessórios.

Tabela 3 - Composição mineralógica dos litotipos estudados, expressa em porcentagem.

\begin{tabular}{|c|c|c|c|c|}
\hline MINERAIS & CALCITA & ACESSÓRIOS & DESIGNAÇÃO & $\begin{array}{c}\text { COR } \\
\text { PREDOMINANTE }\end{array}$ \\
\hline Bege Bahia & 97 & 3 & BB & Bege \\
\hline Mármore Branco & 98 & 2 & MBC & Branco \\
\hline
\end{tabular}


As principais formas de alteração, por ação do intemperismo, observadas no mapeamento de fachadas foram perdas de massa, descoloração, depósitos secundários, desintegração, fissuras, oxidação e eflorescências. A perda de massa se manifesta por meio da alteração parcial da rocha e modificações morfológicas de superfície (relevo áspero). Os depósitos (precipitações) estão relacionados com a formação de crostas claras, em parte resultantes de eflorescências salinas, e/ou originadas pela dissolução/reprecipitação de rejuntes carbonáticos. As manchas negras resultam de reprecipitações associadas com a agregação de fuligem e poeira urbanas, biofilmes escuros com colônias de microflora e/ou micro-organismos (Figura 1).

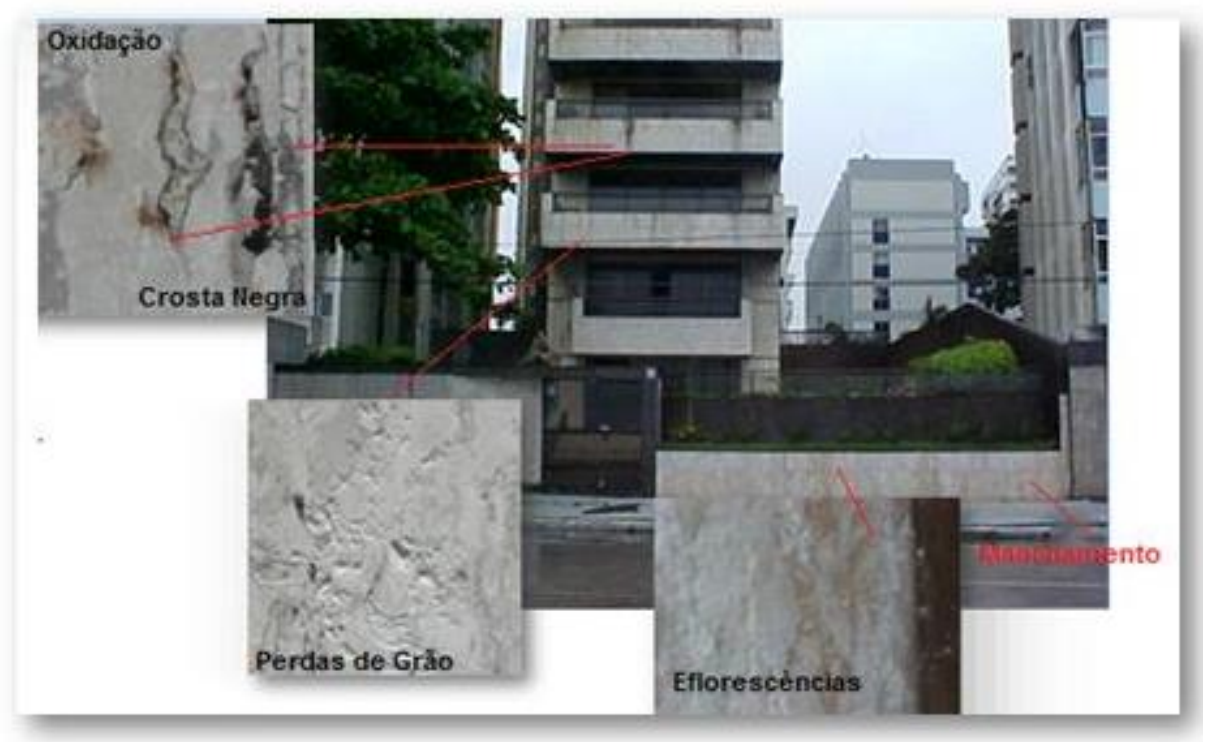

Figura 1 - Ocorrências de patologias em edificação localizada na região litorânea do Recife.

Oxidações acastanhadas ou de tonalidades bege indicam a mobilização e reprecipitação de Fe a partir de minerais férricos disseminados nas placas pétreas ou a partir dos grampos metálicos utilizados na fixação destas placas (Figura 2). As eflorescências estão relacionadas com a dissolução e precipitação do cimento industrial utilizado em várias tentativas de fixação de peças danificadas. Fissuramentos nas placas são pouco frequentes, e, geralmente, correspondem a superfícies irregulares de descontinuidades físicas, não relacionadas com a estrutura interna da rocha. 


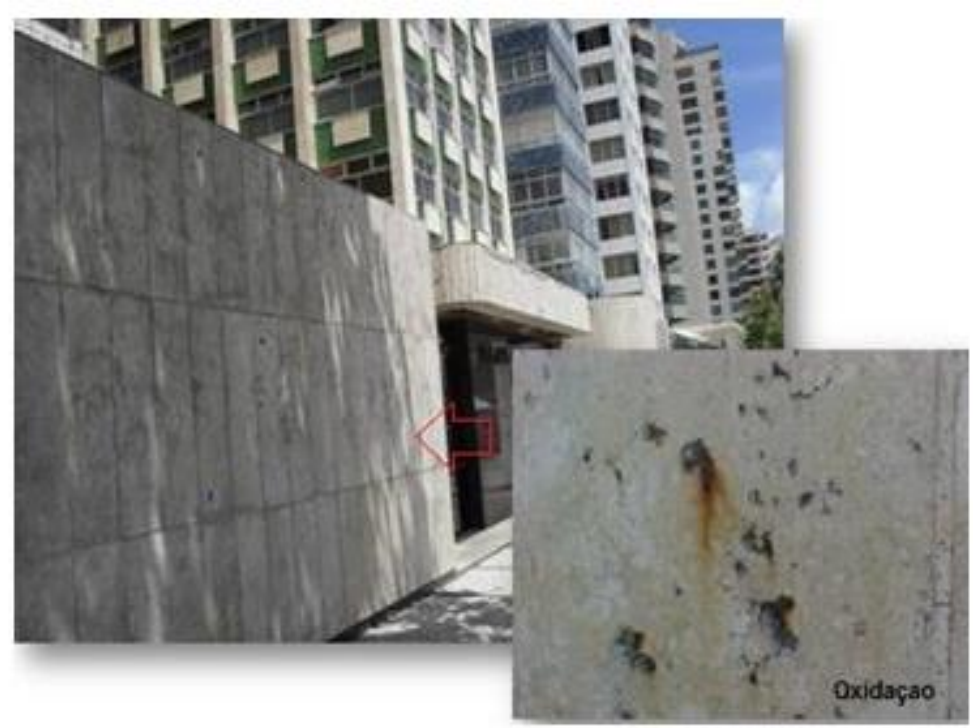

Figura 2 - Aspecto de fachada com revestimento de Bege Bahia, com 20 anos de exposição. Notar a segregação secundária (detalhe) resultante da mobilização e reprecipitação de Fe sob influência intempérica.

As manchas, traduzidas por mudanças de cor, refletem a absorção de água, por parte da placa, seja aquela de amassamento da argamassa de assentamento, ou decorrente das águas de chuva (meteóricas). A porosidade elevada deste tipo de material, acima de $1 \%$ (SILVA, 2008) e, consequentemente a absorção, também elevada (acima de 0,43\%), é fundamental para o manchamento deste litotipo, associado a fatores como as condições ambientais de aplicação deste material, clima de grande pluviosidade $(2.000 \mathrm{~mm}$ de chuvas anuais) e temperatura elevada (média anula de $27^{\circ} \mathrm{C}$ ). A Figura 3 ilustra o fato descrito anteriormente: fachada apresentando mudança da cor original, com manchas.

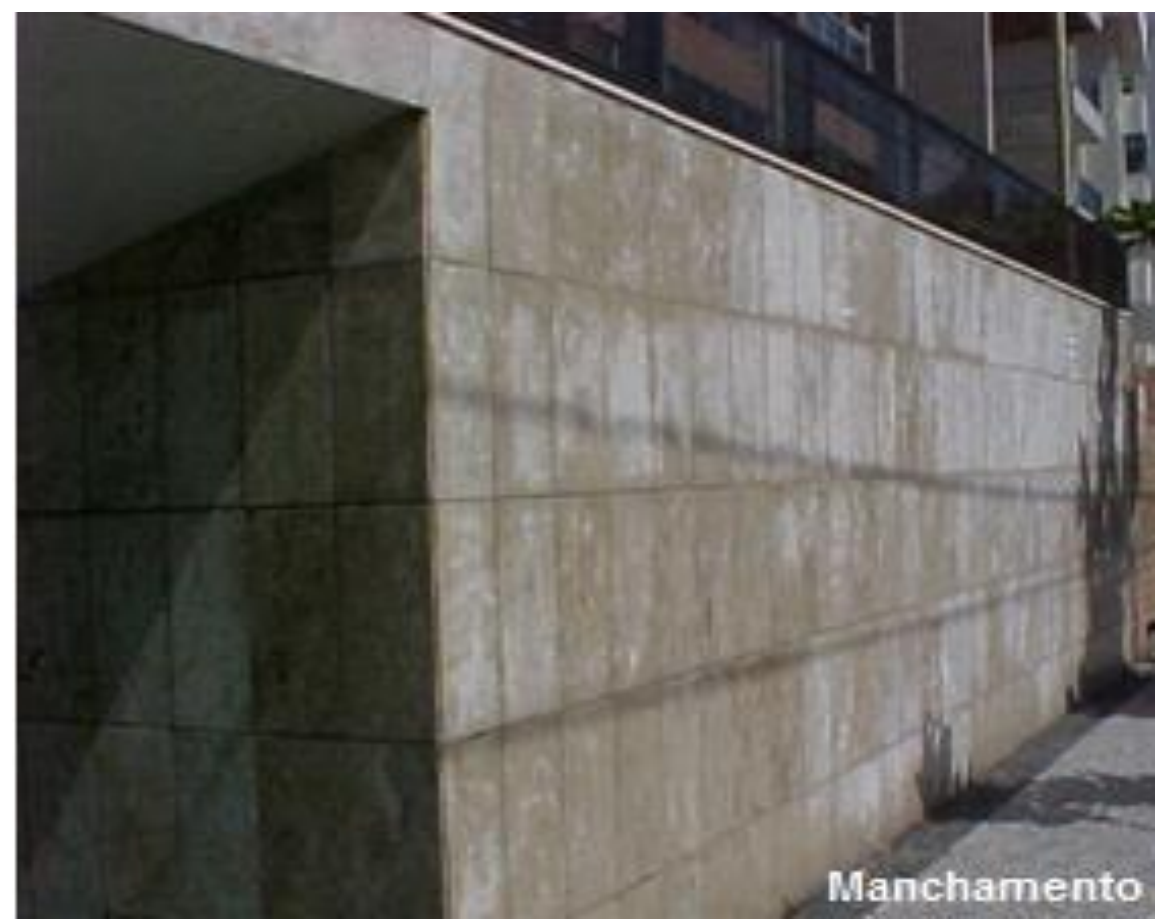

Figura 3 - Manchas observadas em fachada externa de prédio situado na região litorânea do Recife. 
Em condições naturais, rochas de superfície ou de subsuperfície, ou seja, ainda sob influência térmica da insolação, desenvolvem alterações supergênicas. Alterações físicas resultam dos diferenciados coeficientes de dilatação dos vários minerais constituintes das rochas, cuja atuação diuturna resulta em ininterrupto processo de dilatação-contração-dilatação, criando tensões nas estruturas cristalográficas e, desta forma, provocando microfissuramentos. A intensidade deste fenômeno é proporcional à exposição da rocha à insolação e quanto maiores forem os contrastes térmicos diuturnos. Tal processo está nos primórdios da fragmentação ("arenização") das rochas e, inevitavelmente, também é exercido em placas lustradas, particularmente aquelas que compõem fachadas.

No caso dos mármores, particularmente do produto comercial "Travertino" ou "Bege Bahia", os problemas de preservação do lustro e sua vulnerabilidade ao intemperismo, estão vinculados primariamente à composição mineralógica desta rocha. Efetivamente, como calcita $\left(\mathrm{CaCO}_{3}\right)$ e/ou dolomita $\left(\mathrm{CaMg}\left(\mathrm{CO}_{3}\right)_{2}\right)$ são os minerais dominantes em mármores (no caso em estudo a calcita) a vulnerabilidade das suas placas se manifesta acentuadamente tanto no domínio físico quanto no químico. No primeiro caso, em decorrência da baixa dureza destes minerais (na escala de Mohs: 3 para a calcita, e em torno de 3,5 para a dolomita), o que recomenda a não destinação de mármores para pisos. No segundo caso, a vulnerabilidade resulta da forte reatividade com produtos ácidos (inclusive a própria chuva) o que resulta, ao cabo de 5 a 20 anos, em perda acentuada de reflectância do lustro original.

Chuvas ácidas, com pH < 5 ocorrem em domínios fortemente poluídos, incluindo emissões de $\mathrm{SO}_{2}$ (poluição industrial, queima de combustíveis fósseis), que resultam na presença de $\mathrm{H}_{2} \mathrm{SO}_{4}$ diluído nas precipitações pluviométricas, acentuando o poder corrosivo do $\mathrm{H}_{2} \mathrm{CO}_{3}$ diluído, advindo do $\mathrm{CO}_{2}$ atmosférico. Apenas com a diluição de $\mathrm{H}_{2} \mathrm{CO}_{3}$, a água da chuva, estequiometricamente, teria $\mathrm{pH}=5,6$ (ANDREWS et al, 1996). Apesar da frequente aplicação desses produtos em fachadas, estas circunstâncias também não recomendam a aplicação deste produto, ou qualquer tipo de "mármore" como revestimento de fachadas. Na realidade, este litotipo, o "Bege Bahia" é um calcário sedimentar algálico (ou travertino), micrítico a microesparítico, com nucleações constituídas de glomérulos oriundos da fragmentação e retrabalhamento hidrodinâmico de lâminas algálicas, com focos irregulares de recristalização, disseminação difusa ou pontual de óxidos de Fe e, frequentemente, cavidades cársticas (Figura 4).

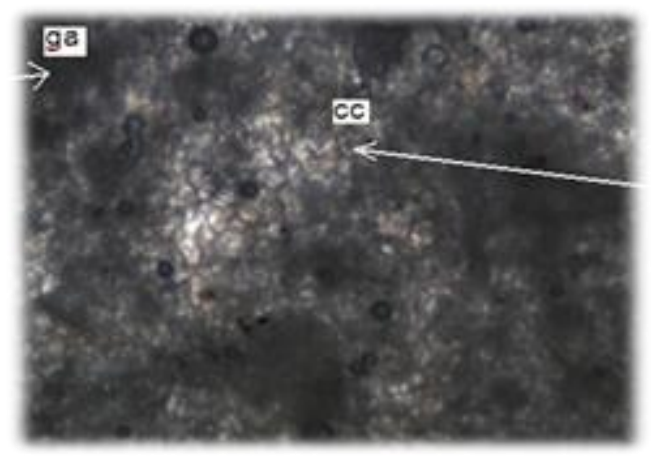

Figura 4 - Aspecto petrográfico geral do calcário travertínico “Bege Bahia”, observando-se glomérulos algálicos (ga) imersos em cimento carbonático (cc). Lâmina petrográfica de rocha sã, LN/80x. 
Em observação petrográfica, a textura micrítica do Bege Bahia se mantém mais ou menos íntegra, porém com nítido aspecto rugoso e sujo devido aos longos anos de exposição do produto ao intemperismo (Figura 5). Nestas circunstâncias, a remobilização do $\mathrm{Fe}$, difuso e não perceptível à observação macroscópica, produz nucleações localizadas, cada vez mais freqüentes e expandidas, terminando por formar filetes de escorrimento em razão da reprecipitação de Fe, perfeitamente visíveis a olho nu e até mesmo à distância (Figura 2). Dependendo da intensidade dos agentes intempéricos (chuvas ácidas, por exemplo) suas placas podem perder drasticamente a reflectância, ao longo de 15 anos.

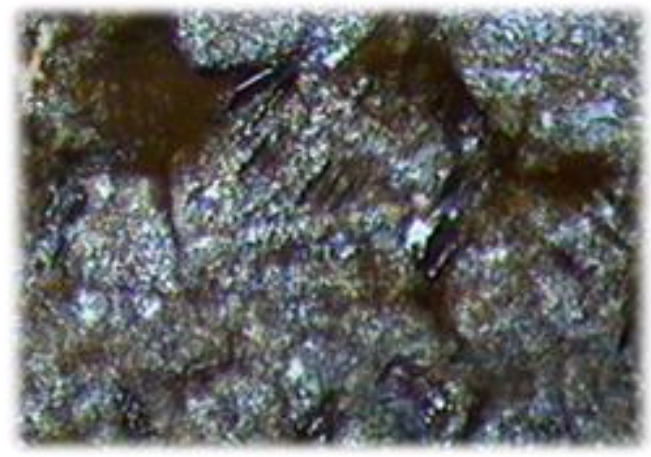

Figura 5 - Superfície de núcleo de recristalização do "Bege Bahia", em placa com 10 anos de exposição ao intemperismo. Notar o aspecto notoriamente "sujo" dessa superfície quando comparado com as condições originais de lustro (figura 4). LN/80x

Em ambientes poluídos, as chuvas mais fortemente acidificadas pela presença de $\mathrm{H}_{2} \mathrm{SO}_{4}$ diluído exercem ataque químico sobre minerais carbonáticos, produzindo-se uma corrosão superficial (erosão cárstica) e a precipitação de gipsita $\left(\mathrm{CaSO}_{4} \cdot 2 \mathrm{H}_{2} \mathrm{O}\right)$, mineral de baixa dureza, com solubilidade de $2.100 \mathrm{mg} / \mathrm{L}$ para $\mathrm{pH}$ próximo a 7, temperatura de $25^{\circ} \mathrm{C}$ e pressão de 1 bar, segundo Freeze \& Cherry (1979), sendo portanto facilmente removido pela própria água das chuvas. Entretanto, devido à porosidade e microfissuras da rocha, as águas da chuva podem penetrar na placa pétrea, e em seguida evaporar. Neste caso, a gipsita pode transitoriamente cristalizar e contribuir, através do crescimento de cristais (que geram tensões no interior dos poros da rocha), para a desintegração física da pedra por meio de um processo conhecido como degradação ambiental salina (SMITH \& McGREEVY, 1999).

Assim como o ácido sulfúrico, que é gerado a partir de óxidos de enxofre na atmosfera, o ácido clorídrico pode ser produzido na atmosfera de ambientes litorâneos, a partir de reação do cloreto de sódio $(\mathrm{NaCl})$ marinho com ácido sulfúrico obtido da oxidação do $\mathrm{SO}_{2}$. É a maresia, ou spray marinho, formada por gotículas micrométricas que contém e provê o $\mathrm{NaCl}$. O $\mathrm{HCl}$ é um ácido forte, e ainda que diluído em águas de chuva, é também bastante reativo quando incidente sobre rochas carbonáticas. Neste caso, o processo reativo gera o cloreto de cálcio $\left(\mathrm{CaCl}_{2}\right)$, passível de cristalizar na porosidade e fissuramento destas rochas.

Diversos mecanismos de reatividade supergênica podem gerar sais que são capazes de danificar a textura das rochas ornamentais, em particular no caso de rochas carbonáticas. 0 processo se faz por uma sucessão de eventos pluviométricos acidificados, gerando hidrólise de minerais, através de uma sucessão de molhagem-secagem. Quando molhadas as rochas estão sujeitas a processos hidrolíticos, que formam sais, na maior parte dos casos solúveis, capazes de se infiltrar na sua porosidade e/ou fissuras. Por secagem, o solvente se evapora, e o soluto salino 
precipita, originando pressões internas capazes de microestilhaçar a superfície dos minerais contíguos e/ou expandir os fissuramentos internos das rochas. Estas rupturas físicas contribuem de uma forma geral, e com o passar do tempo, para perdas de massa e aumento de porosidade, uma vez que os sais precipitados podem ser removidos por soluções salinas neófitas, gerando um ciclo permanente de cristalizações e dissoluções internas. O que torna este mecanismo importante é que esses limiares de temperatura e de umidade podem ser atravessados diversas vezes durante um só dia, produzindo inúmeros ciclos de expansão e contração que levam à fadiga do material lítico. Smith \& McGreevy (1999) admitem a existência de algumas dúvidas sobre a real eficácia dos mecanismos de expansão térmica diferencial, mas ela pode perfeitamente contribuir para o colapso das rochas, mesmo que outros mecanismos intempéricos também estejam presentes.

\section{CONCLUSÕES}

Os edifícios cujos revestimentos foram estudados apresentaram alterações como: manchas (37\%), perda de brilho (25\%), perda de massa (13\%), oxidação (10\%), eflorescências (5\%), fissuras (5\%), crostas negras (4\%) e fungos (1\%). Estas patologias tornam-se intensificadas pelo regime climático tropical e pela cristalização de sais nas microfissuras das rochas, além da abrasão por particulados transportados pelo vento, o que contribui para perda de brilho.

O estudo ressalta a importância do reconhecimento geológico dos materiais pétreos empregados nas edificações, tanto para permitir a escolha dos materiais mais adequados como na busca de soluções de conservação e manutenção das edificações. Em ambientes litorâneos, as sucessões de transferências de fases gasosas e líquidas entre a atmosfera e as placas pétreas de revestimento propiciam a acumulação de sais que causam danos a estes revestimentos.

As condições climáticas de Recife favorecem a ocorrência e alternância natural destes ciclos. Consideradas, ainda, as oscilações diárias da umidade relativa, com valores maiores e menores do que $80 \%$, que favorecem a cristalização ou a dissolução dos sais, isto é, condições ideais para desencadear processos de alteração nos revestimentos. Tais circunstâncias e suas consequências são facilmente observadas nas rochas de revestimento encontradas na região da orla, como destacamentos líticos, eflorescências, desagregações e manchamentos.

Os materiais de constituição carbonática geram problemas de alterabilidade e devem ser aplicados, prioritariamente, em uso interno. O aumento da poluição atmosférica, devido principalmente pela ação antrópica, tem produzido gases que geram ácidos que aceleram a degradação das rochas e dos monumentos. Cada poluente tem uma ação importante e o conhecimento dos mecanismos desses processos objetiva evitar as patologias que danos à construção e aos monumentos.

Em síntese, estes seriam aspectos restritivos comuns aos mármores, notadamente no caso de calcários sedimentares. Estes produtos apresentam alterabilidade precocemente, por vezes com menos de 5 anos de aplicação.

\section{REFERÊNCIAS BIBLIOGRÁFICAS}

1. AIRES-BARROS L., 1991. Alteração e alterabilidade de rochas. Lisboa, Univ. Técn. Lisboa/Inst. Nac. Invest. Cient., 384 pp. 
2. ANDREWS, J. E.; BRIMBLECOMBE, P.; JICKELLS, T. D. The atmosphere. In_An Introduction to Environmental Chemistry. Oxford, Ed. Blackwell Science Ltd., 1996.

3. B.J., Smith; J. P., MacGreevy, 1999. Degradação da pedra urbana e deposição ácida: uma introdução ao problema e às suas causas. Tradução por Antonio de Borja Araújo, 2004, 12p.

4. BERNER, E. K.; BERNER, R. A. The Global Water Cycle: Geochemistry and Environment. Cap. 3: Rainwater and Atmospheric Chemistry. Ed. Prentice-Hall, Inc, Englewood Cliffs, New Jersey, 396 p., (1987).

5. BICZÓK, I. 1972. Corrosion y protección del hormigon. Ediciones Urmo, 715p. Bilbao.

6. FREEZE, R. A.; CHERRY, J. A. Groundwater. New Jersey. Englewood Cliffs, Prentice Hall, 604 p, 1979.

7. FRASCÁ, M. H. B. O. 2003. Estudos experimentais de alteração acelerada em rochas graníticas para revestimento, 282p. Tese de Doutorado, Instituto de Geociências, Universidade de São Paulo, São Paulo.

8. MEHTA, P. K. ; MONTEIRO, P. J. M. Concreto: estrutura, propriedades e materiais. São Paulo, Pini, 1994.

9. RIBEIRO, W. J. M. 2011. Estudo comparativo de alterabilidade acelerada de três fácies comerciais do sienito Marrom Imperial, 130p. Dissertação de Mestrado, Programa de PósGraduação em Engenharia Mineral, Universidade Federal de Pernambuco, Recife.

10. SILVA, S. A. 2008. Estado da arte na alterabilidade de places pétreas: estudo de casos na região litorânea do Recife - PE, 240p. Dissertação de Mestrado, Programa de Pós-Graduação em Engenharia Mineral, Universidade Federal de Pernambuco, Recife. 